\title{
Langmuir-Blodgett Monolayers of Partially Fluorinated Ionic Liquids as Two- Dimensional, More Sustainable Functional Materials and Coatings
}

\section{ELECTRONIC SUPPORTING INFORMATION}

Thorben Sieling, Jens Christoffers and Izabella Brand*

Department of Chemistry, University of Oldenburg, 26111 Oldenburg, Germany

Number of pages: $\quad 13$

Number of figures: $\quad 8$

Number of tables: $\quad 4$

\section{Table of content:}

SI.1 Langmuir Monolayers of FILs at the Air-Water Interface $\quad$ S2

SI.2 XP Spectra of FILs on the Gold Surface $\quad$ S3

SI.3 Isotropic Optical Constants of $[\mathrm{Im}]^{+}[\mathrm{I}]^{-}$and the Calculation of the PM IRRA $\quad$ S4 Spectrum of Randomly Distributed Molecules in a Monolayer Thick Film

SI.4 Quantum Chemical Calculation $\quad$ S6

SI.5 Deconvolution of the PM IRRA Spectra of FILs in LB Monolayers S10

$\begin{array}{lll}\text { SI.6 Contact Angle Measurement } & \text { S12 }\end{array}$

* To whom correspondence should be addressed, I. Brand: izabella.brand@ uni-oldenburg.de 
$[\mathrm{Im}]^{+}[\mathrm{TfO}]^{-},\left[1,2,3-\mathrm{Tria}^{+}[\mathrm{TfO}]^{-}\right.$and $[1,2,4-\mathrm{Tria}]^{+}[\mathrm{TfO}]^{-}$fluorinated ionic liquids (FILs) form rather unstable monolayers at the air-water interface. The surface pressure $(\pi)$ versus area per molecule $(A)$ isotherms at the air-water interface of these FILs are shown in Figure S1.

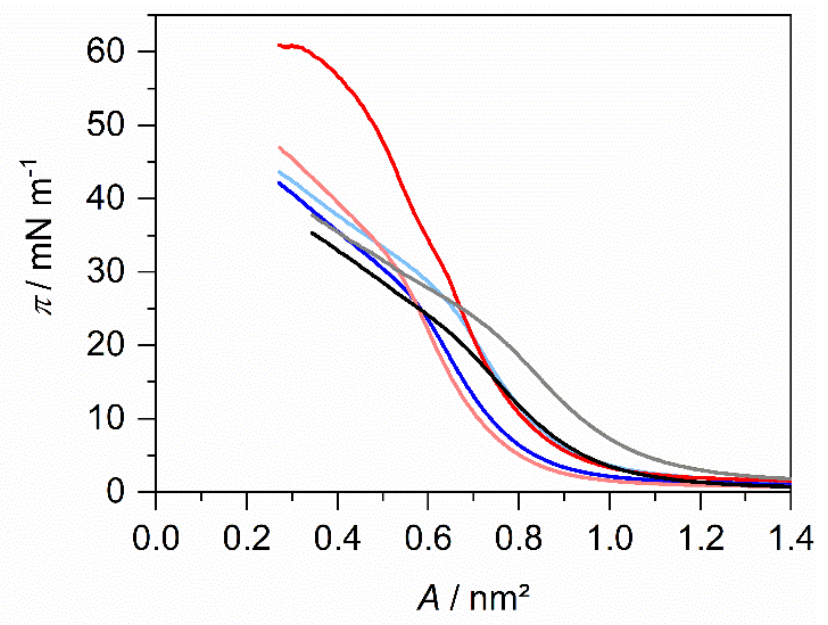

Figure S1. Surface pressure versus area per molecule isotherms of FILs on the air-water interface: gray and black: $[\mathrm{Im}]^{+}[\mathrm{TfO}]^{-}$, red: $[1,2,3-\text { Tria }]^{+}[\mathrm{TfO}]^{-}$and blue: $[1,2,4-\text { Tria }]^{+}[\mathrm{TfO}]^{-}$.

A significant deviation in the shape of the $\pi-A$ isotherms of the FILs is observed in the independent measurements. The lift-off area of the studied monolayers is in the range of $1.15<$ $A_{0}<0.90 \mathrm{~nm}^{2}$. It depends on the volume of the FIL placed at the air-water interface. The collapse of all monolayers is not well defined. During compression the surface pressure increases to $35-60 \mathrm{mN} \mathrm{m}^{-1}$. These results indicate that at the air-water interface cations of FILs are surface active but form poorly defined, aggregated layers. 


\section{SI.2 XP Spectra of FILs on the Gold Surface}

Figure S2 shows survey XP spectra of $[\mathrm{Im}]^{+}[\mathrm{TfO}]^{-} \mathrm{LB}$ monolayers on the gold surface.

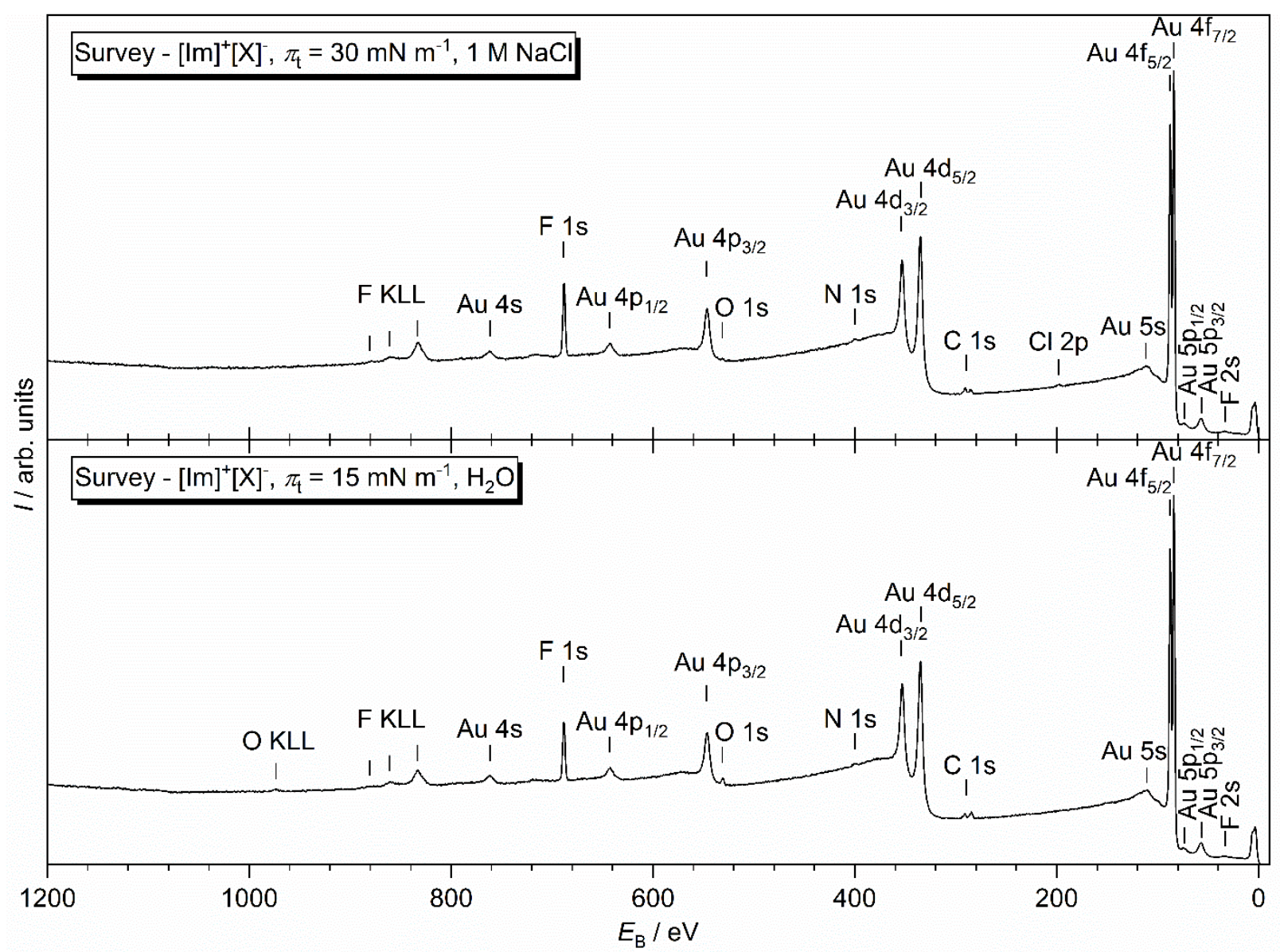

Figure S2. Survey XP spectra of the LB monolayers of $[\mathrm{Im}]^{+}[\mathrm{TfO}]^{-}$transferred from the $1 \mathrm{M}$ $\mathrm{NaCl}$ (top) and pure aqueous subphase (bottom) onto the gold surface. $I$ - Intensity, $E_{\mathrm{B}}$ - binding energy.

The spectrum of $[\mathrm{Im}]^{+}[\mathrm{TfO}]^{-} \mathrm{LB}$ monolayer transferred from $\mathrm{NaCl}$ subphase reveals the presence of the following elements: $\mathrm{Au}, \mathrm{Cl}, \mathrm{C}, \mathrm{O}, \mathrm{N}$, and $\mathrm{F}$. In the monolayer transferred from pure aqueous subphase $\mathrm{Au}, \mathrm{C}, \mathrm{O}, \mathrm{N}$, and $\mathrm{F}$ are detected. In addition, in this monolayer, traces of $\mathrm{S}$ are found. Figure S3 shows a S 2p XP high resolution spectrum of the monolayer. The fitted $\mathrm{XP}$ spectrum shows two lines at binding energies $E_{\mathrm{B}}=167.7 \mathrm{eV}\left(\mathrm{S} 2 \mathrm{p}_{3 / 2}\right)$ and $E_{\mathrm{B}}=169.0 \mathrm{eV}$ (S 2 $\left.\mathrm{p}_{1 / 2}\right)$. These $E_{\mathrm{B}}$ are characteristic for $\underline{\mathrm{S}}-\mathrm{O}$ species. ${ }^{1,2}$ 


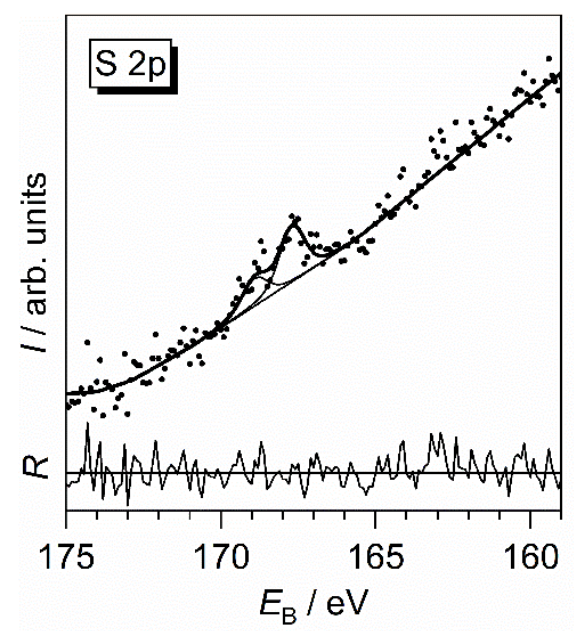

Figure S3. High resolution $\mathrm{S} 2 \mathrm{p}$ XP spectrum of $[\mathrm{Im}]^{+}[\mathrm{X}]^{-} \mathrm{LB}$ monolayer transferred from aqueous subphase. Pass energy $=70 \mathrm{eV}$, dwell time $=1 \mathrm{~s}$. Fitted with same full width half maxima and a fixed doublet separation of $1.2 \mathrm{eV}$.

\section{SI.3 Isotropic Optical Constants of [Im $]^{+}[\mathrm{I}]^{-}$and the Calculation of the PM IRRA Spectrum of}

Randomly Distributed Molecules in a Monolayer Thick Film

Isotropic optical constants of $[\mathrm{Im}]^{+}[\mathrm{I}]^{-} \quad([1,3-\mathrm{bis}(1 \mathrm{H}, 1 \mathrm{H}, 2 \mathrm{H}, 2 \mathrm{H}$-perfluorooctyl)imidazolium iodide]), synthesized as reported in, ${ }^{3}$ were determined from transmission IRS measurement of $1 \%$ FIL in a $\mathrm{KBr}$ pellet (Spectroscopy grade, Fisher Scientific U.K. Limited, Loughborough, UK). In the $[\mathrm{Im}]^{+}[\mathrm{I}]^{-}$FIL only the $[\mathrm{Im}]^{+}$cation absorbs the IR light. The attenuation coefficient $(k)$ was extracted with Lambert-Beer's-law and Kramer-Kroenig transformation was used to determine the refractive index $(n)$ of $[\mathrm{Im}]^{+}$cations in the 1800 $900 \mathrm{~cm}^{-1}$ spectral region. The isotropic optical constants are shown in figure $\mathrm{S} 4$. 


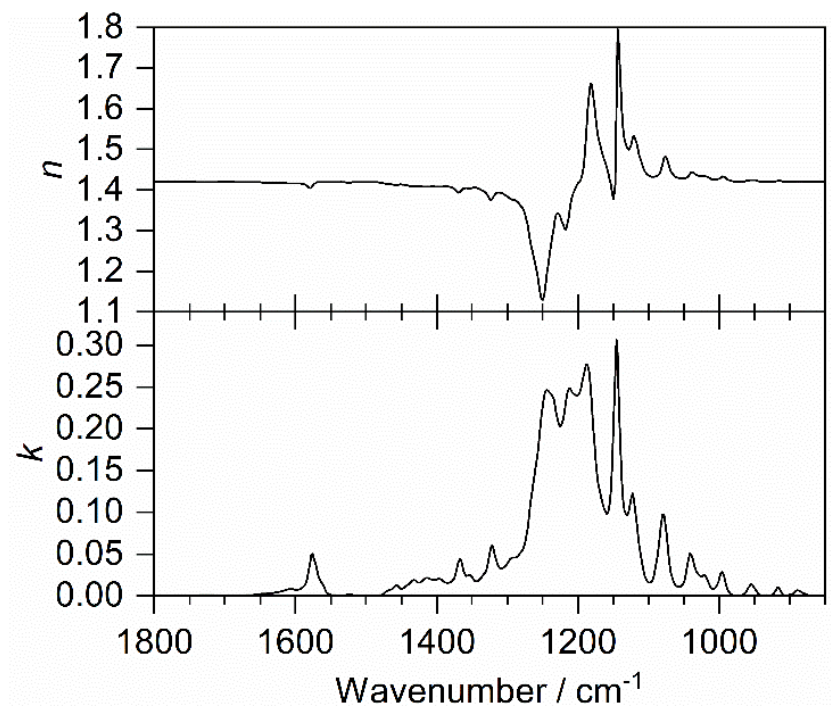

Figure S4. Isotropic optical constants: attenuation coefficient $(k)$ and refractive index $(n)$ of $[\operatorname{Im}]^{+}[\mathrm{I}]^{-}$.

The isotropic optical constants are required to calculate a PM IRRA spectrum of randomly distributed amphiphilic $[\mathrm{Im}]^{+}$cations in a monolayer thick film. ${ }^{4}$ In the calculation the angle of the incidence of the incoming IR radiation is set to $80^{\circ}$. The isotropic optical constants of gold are taken from ${ }^{5}$. Air is not absorbing in the $1800-900 \mathrm{~cm}^{-1}$ spectral region, thus in the calculation $k=0$ and $n=1$. To calculate the PM IRRA spectrum of randomly distributed [Im] ${ }^{+}$ cations the surface concentration $(\Gamma)$ and the thickness of the monolayer thick film $(d)$ have to be known. The surface concentration of the $[\mathrm{Im}]^{+}$cations is calculated from Langmuir monolayers shown in figure 2. Table S1 lists the area per molecule of the FILs at the transfer pressure, the calculated $\Gamma$ and surface coverage $\left(\Theta=\Gamma_{\mathrm{t}} / \Gamma_{\text {lim }}\right)$.

Table S1. Area per molecule $\left(A_{\mathrm{t}}\right)$ at the surface pressure $\left(\pi_{\mathrm{t}}\right)$ of the monolayer transfer, the surface concentration $\left(\Gamma_{\mathrm{t}}\right)$ of the FIL $\mathrm{S}_{\mathrm{S}}$ in the LB monolayers at the transfer pressure, the maximal surface concentration $\left(\Gamma_{\text {lim }}\right)$, and the surface coverage $(\Theta)$ in the LB monolayer on the gold surface.

\begin{tabular}{|c|c|c|c|c|c|c|}
\hline FIL & $\begin{array}{c}\pi_{\mathrm{t}} / \\
\mathbf{m N ~ m}^{-1}\end{array}$ & $\begin{array}{l}A_{\mathrm{t}} / \\
\mathbf{n m}^{2}\end{array}$ & $\underset{\mathbf{n m}^{2}}{A_{\lim } /}$ & $\begin{array}{l}\Gamma_{\mathrm{t}} / \\
10^{-10} \mathrm{~mol} \mathrm{~cm}^{-2}\end{array}$ & $\begin{array}{c}\Gamma_{\lim } / \\
10^{-10} \mathrm{~mol} \mathrm{~cm}^{-2}\end{array}$ & $\boldsymbol{\Theta}$ \\
\hline$[\mathrm{Im}]^{+}[\mathrm{TfO}]^{-}$ & 15 & 0.82 & 0.55 & 2.0 & 3.0 & 0.68 \\
\hline$[1,2,4-\text { Tria }]^{+}[\mathrm{TfO}]^{-}$ & 15 & 0.79 & 0.55 & 2.1 & 3.0 & 0.69 \\
\hline$[1,2,3-\text { Tria }]^{+}[\mathrm{TfO}]^{-}$ & 15 & 0.77 & 0.54 & 2.2 & 3.0 & 0.71 \\
\hline$[\mathrm{Im}]^{+}[\mathrm{TfO}]^{-}$ & 30 & 0.70 & 0.55 & 2.4 & 3.0 & 0.80 \\
\hline$[1,2,4 \text {-Tria }]^{+}[\mathrm{TfO}]^{-}$ & 30 & 0.68 & 0.55 & 2.4 & 3.0 & 0.80 \\
\hline$[1,2,3 \text {-Tria }]^{+}[\mathrm{TfO}]^{-}$ & 30 & 0.62 & 0.54 & 2.7 & 3.0 & 0.89 \\
\hline
\end{tabular}


The transfer ratio of the FILs monolayers onto the $\mathrm{Au}$ surface is 1.03, indicating that the monolayer present at the liquid-air interface is quantitatively transferred onto the gold surface. Therefore, the surface coverage calculated from the Langmuir monolayer is used in the calculation of the PM IRRA spectrum.

The thickness of a monolayer of the amphiphilic cation is set to $d=1.6 \mathrm{~nm}$. This value is taken from quantum chemical calculations (SI.4) of the cation structure. In the calculation of the $d$ the van der Waals radii ${ }^{6}$ are added to the extracted interatomic distance of $1.1 \mathrm{~nm}$ along the chain (Figure S5). A distance of $0.2 \mathrm{~nm}$ is added to the calculated cation length, due to uneven distribution of the amphiphilic cations in the monolayer. ${ }^{7}$

\section{SI.4 Quantum Chemical Calculation}

The geometry of the $[\mathrm{Im}]^{+}$cation was optimized (B3LYP/def2-TZVP) for various conformers using Gaussian 16 Rev. A.03 (Gaussian Inc., Wallingford, USA). The minimum energy structure ( $E=-3437.249259$ hartree) exhibits the two partly fluorinated chains adjacent to each other with methylene groups in gauche and fluorinated parts in helical conformation (Figure S5). The Cartesian coordinates are given in Table S2. Subsequently, harmonic frequencies were calculated (Table S3).
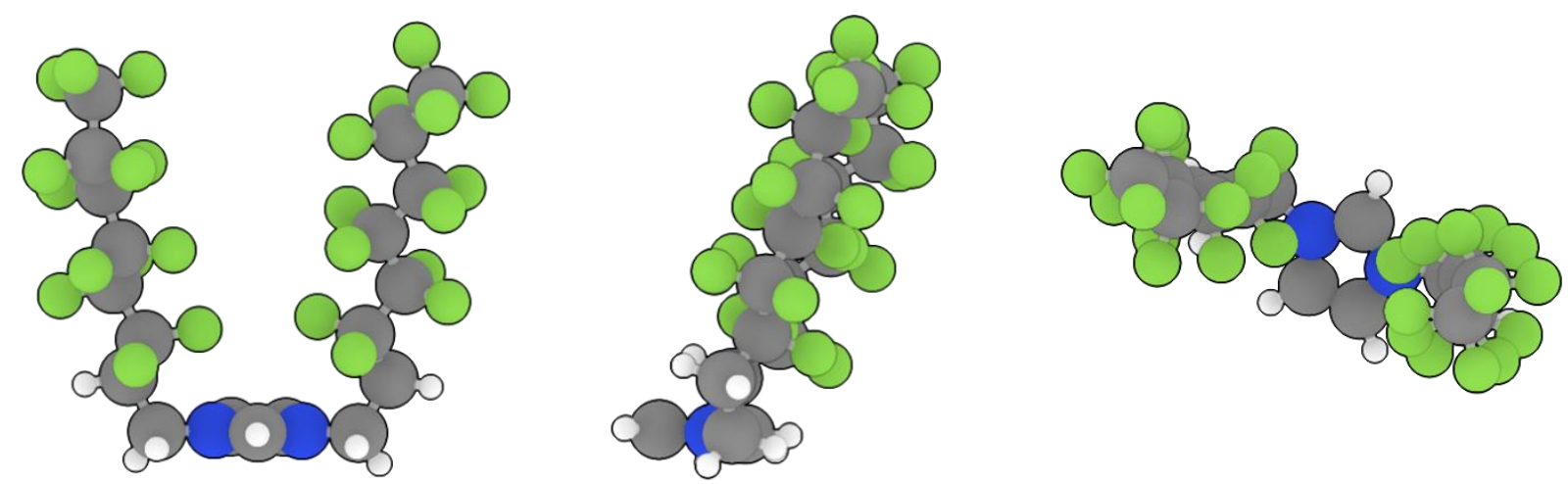

Figure S5. Minimum energy conformer of the $[\mathrm{Im}]^{+}$cation (B3LYP/def2-TZVP). Color code: $\mathrm{H}$ - white, C - grey, N - blue, F-green. 
Table S2. Cartesian coordinates of the minimum energy conformer of the $[\mathrm{Im}]^{+}$cation (B3LYP/def2-TZVP).

\begin{tabular}{rrrr}
\hline Atomic No. & $\boldsymbol{x} / \AA$ & $\boldsymbol{y} / \AA$ & $\boldsymbol{z} / \AA$ \\
\hline 6 & -0.07638 & 4.80982 & 0.66999 \\
1 & -0.00435 & 4.40414 & 1.66435 \\
7 & 0.9524 & 5.10308 & -0.12443 \\
7 & -1.21144 & 5.0763 & 0.02458 \\
6 & 0.45574 & 5.56913 & -1.32489 \\
6 & -0.89711 & 5.55228 & -1.23194 \\
6 & 2.37996 & 4.96613 & 0.22184 \\
1 & 2.45107 & 4.9409 & 1.30752 \\
1 & 2.87261 & 5.87605 & -0.11706 \\
6 & -2.56954 & 4.88714 & 0.56762 \\
1 & -2.46963 & 4.77368 & 1.64459 \\
1 & -3.12264 & 5.80665 & 0.38093 \\
6 & -3.33315 & 3.7074 & -0.03517 \\
1 & -4.33296 & 3.71629 & 0.40208 \\
1 & -3.45194 & 3.81433 & -1.11274 \\
6 & -2.69039 & 2.3545 & 0.24924 \\
6 & -3.6526 & 1.16286 & -0.05208 \\
6 & -2.98207 & -0.2566 & -0.04941 \\
1 & -1.64935 & 5.84789 & -1.94131 \\
1 & 1.09641 & 5.88514 & -2.12888 \\
6 & -4.01609 & -1.43454 & 0.06891 \\
6 & -3.42967 & -2.82409 & -0.35967 \\
6 & -4.27557 & -4.0547 & 0.11004 \\
6 & 3.07577 & 3.75318 & -0.4002 \\
1 & 4.14988 & 3.89886 & -0.28717 \\
1 & 2.86833 & 3.679 & -1.46823 \\
6 & 2.70496 & 2.43549 & 0.26794 \\
6 & 3.48015 & 1.21986 & -0.33188 \\
6 & 3.33526 & -0.12687 & 0.46228 \\
6 & 3.75756 & -1.39051 & -0.37208 \\
6 & 4.03847 & -2.65539 & 0.51089 \\
\hline & & &
\end{tabular}

\begin{tabular}{rrrr}
\hline Atomic No. & $\boldsymbol{x} / \AA$ & $\boldsymbol{y} / \AA$ & $\boldsymbol{z} / \AA$ \\
\hline 6 & 3.48015 & 1.21986 & -0.33188 \\
6 & 3.33526 & -0.12687 & 0.46228 \\
6 & 3.75756 & -1.39051 & -0.37208 \\
6 & 4.03847 & -2.65539 & 0.51089 \\
6 & 4.06932 & -4.00353 & -0.28427 \\
9 & -1.56299 & 2.20984 & -0.50589 \\
9 & -2.30724 & 2.29624 & 1.55481 \\
9 & -4.19249 & 1.38509 & -1.2716 \\
9 & -4.63947 & 1.20575 & 0.86845 \\
9 & -2.28697 & -0.38617 & -1.19581 \\
9 & -2.12738 & -0.326 & 0.98872 \\
9 & -5.07606 & -1.1575 & -0.7155 \\
9 & -4.42677 & -1.50256 & 1.34915 \\
9 & -3.35599 & -2.86243 & -1.70137 \\
9 & -2.18979 & -2.95823 & 0.15349 \\
9 & -4.19078 & -4.2112 & 1.42942 \\
9 & -5.5555 & -3.89575 & -0.23225 \\
9 & -3.79915 & -5.14695 & -0.48388 \\
9 & 1.3658 & 2.21337 & 0.1296 \\
9 & 2.95975 & 2.51025 & 1.60307 \\
9 & 3.03545 & 1.05614 & -1.59839 \\
9 & 4.78774 & 1.55505 & -0.37657 \\
9 & 2.05003 & -0.26991 & 0.83892 \\
9 & 4.10478 & -0.03966 & 1.56294 \\
9 & 2.76553 & -1.66753 & -1.24027 \\
9 & 4.87409 & -1.09674 & -1.06631 \\
9 & 3.08038 & -2.75776 & 1.45427 \\
9 & 5.23143 & -2.50285 & 1.1102 \\
9 & 2.84917 & -4.33256 & -0.70501 \\
9 & 4.88383 & -3.90373 & -1.33669 \\
9 & 4.51793 & -4.96175 & 0.5234 \\
\hline & & & \\
\hline
\end{tabular}


Table S3. Harmonic frequencies of the $[\mathrm{Im}]^{+}$cation minimum energy conformer (B3LYP/def2TZVP).

\begin{tabular}{rrr} 
No. $\begin{array}{l}\text { Wavenumber / } \\
\text { cm }^{-1}\end{array}$ & \multicolumn{2}{c}{ KM-Intensity / } \\
\hline 1 & 3.53 & 0.05 \\
2 & 5.78 & 0.03 \\
3 & 7.28 & 0.05 \\
4 & 13.28 & 0.12 \\
5 & 17.75 & 0.52 \\
6 & 29.01 & 0.90 \\
7 & 31.18 & 1.10 \\
8 & 33.05 & 0.06 \\
9 & 37.74 & 0.76 \\
10 & 44.53 & 0.67 \\
11 & 48.17 & 1.25 \\
12 & 51.11 & 0.57 \\
13 & 53.04 & 0.41 \\
14 & 56.42 & 1.37 \\
15 & 66.39 & 0.70 \\
16 & 67.69 & 0.67 \\
17 & 74.11 & 0.81 \\
18 & 83.10 & 1.70 \\
19 & 116.91 & 0.62 \\
20 & 126.99 & 1.89 \\
21 & 138.75 & 1.03 \\
22 & 142.12 & 2.59 \\
23 & 149.84 & 0.18 \\
24 & 171.19 & 1.07 \\
25 & 176.93 & 0.20 \\
26 & 182.76 & 0.32 \\
27 & 201.56 & 7.62 \\
28 & 206.83 & 5.59 \\
29 & 207.65 & 2.49 \\
30 & 212.39 & 0.90 \\
31 & 218.29 & 0.88 \\
32 & 228.49 & 0.25 \\
33 & 229.45 & 0.20 \\
34 & 239.00 & 0.18 \\
35 & 239.79 & 0.05 \\
36 & 248.23 & 1.00 \\
37 & 254.47 & 0.01 \\
38 & 255.74 & 0.18 \\
39 & 257.04 & 0.28 \\
40 & 257.39 & 0.54 \\
41 & 288.34 & 3.45 \\
42 & 288.55 & 5.34 \\
\hline & & \\
\hline & &
\end{tabular}

\begin{tabular}{|c|c|c|}
\hline No. & $\begin{array}{l}\text { Wavenumber / } \\
\mathrm{cm}^{-1}\end{array}$ & $\begin{array}{l}\text { IR-Intensity / } \\
\mathrm{KM} / \mathrm{mol}\end{array}$ \\
\hline 43 & 299.82 & 0.50 \\
\hline 44 & 308.63 & 0.11 \\
\hline 45 & 309.16 & 0.56 \\
\hline 46 & 313.03 & 1.15 \\
\hline 47 & 313.26 & 0.41 \\
\hline 48 & 342.67 & 0.59 \\
\hline 49 & 342.83 & 0.23 \\
\hline 50 & 351.60 & 4.48 \\
\hline 51 & 355.45 & 0.25 \\
\hline 52 & 360.69 & 0.07 \\
\hline 53 & 361.86 & 1.34 \\
\hline 54 & 370.01 & 0.56 \\
\hline 55 & 370.36 & 0.59 \\
\hline 56 & 379.74 & 2.19 \\
\hline 57 & 380.80 & 0.01 \\
\hline 58 & 400.45 & 7.41 \\
\hline 59 & 402.64 & 4.82 \\
\hline 60 & 410.05 & 3.99 \\
\hline 61 & 415.87 & 43.37 \\
\hline 62 & 456.90 & 1.87 \\
\hline 63 & 464.99 & 0.20 \\
\hline 64 & 465.23 & 0.43 \\
\hline 65 & 519.93 & 12.27 \\
\hline 66 & 523.96 & 4.18 \\
\hline 67 & 524.15 & 21.62 \\
\hline 68 & 527.40 & 6.20 \\
\hline 69 & 532.53 & 4.88 \\
\hline 70 & 532.77 & 0.59 \\
\hline 71 & 564.15 & 21.33 \\
\hline 72 & 565.82 & 16.95 \\
\hline 73 & 574.59 & 2.33 \\
\hline 74 & 575.64 & 0.76 \\
\hline 75 & 594.35 & 13.58 \\
\hline 76 & 599.69 & 0.27 \\
\hline 77 & 600.95 & 8.68 \\
\hline 78 & 615.39 & 0.83 \\
\hline 79 & 617.44 & 1.70 \\
\hline 80 & 648.84 & 13.17 \\
\hline 81 & 652.07 & 167.08 \\
\hline 82 & 659.80 & 0.24 \\
\hline 83 & 670.43 & 7.82 \\
\hline 84 & 684.79 & 18.99 \\
\hline
\end{tabular}




\begin{tabular}{|c|c|c|}
\hline No. & $\begin{array}{l}\text { Wavenumber / } \\
\mathrm{cm}^{-1}\end{array}$ & $\begin{array}{l}\text { IR-Intensity / } \\
\mathrm{KM} / \mathrm{mol}\end{array}$ \\
\hline 85 & 699.44 & 187.13 \\
\hline 86 & 702.06 & 3.42 \\
\hline 87 & 707.45 & 3.48 \\
\hline 88 & 708.07 & 6.19 \\
\hline 89 & 732.18 & 45.39 \\
\hline 90 & 733.48 & 12.69 \\
\hline 91 & 756.88 & 31.03 \\
\hline 92 & 766.63 & 7.12 \\
\hline 93 & 767.33 & 16.20 \\
\hline 94 & 856.70 & 25.00 \\
\hline 95 & 882.53 & 0.65 \\
\hline 96 & 890.11 & 9.93 \\
\hline 97 & 897.19 & 12.00 \\
\hline 98 & 931.11 & 1.98 \\
\hline 99 & 934.64 & 0.88 \\
\hline 100 & 962.47 & 10.55 \\
\hline 101 & 969.63 & 15.58 \\
\hline 102 & 1012.40 & 18.79 \\
\hline 103 & 1018.63 & 16.17 \\
\hline 104 & 1050.58 & 20.63 \\
\hline 105 & 1052.61 & 8.77 \\
\hline 106 & 1076.18 & 66.48 \\
\hline 107 & 1081.43 & 64.57 \\
\hline 108 & 1115.10 & 35.15 \\
\hline 109 & 1121.83 & 43.18 \\
\hline 110 & 1127.12 & 12.70 \\
\hline 111 & 1127.45 & 27.47 \\
\hline 112 & 1130.13 & 20.85 \\
\hline 113 & 1146.76 & 136.09 \\
\hline 114 & 1147.52 & 59.69 \\
\hline 115 & 1156.95 & 25.91 \\
\hline 116 & 1157.61 & 28.33 \\
\hline 117 & 1167.73 & 23.81 \\
\hline 118 & 1169.21 & 130.55 \\
\hline 119 & 1176.42 & 155.30 \\
\hline 120 & 1177.99 & 350.03 \\
\hline 121 & 1180.06 & 53.95 \\
\hline 122 & 1185.42 & 64.92 \\
\hline 123 & 1186.42 & 102.46 \\
\hline 124 & 1194.52 & 149.40 \\
\hline 125 & 1196.21 & 4.03 \\
\hline 126 & 1198.09 & 265.92 \\
\hline
\end{tabular}

\begin{tabular}{|c|c|c|}
\hline No. & $\begin{array}{l}\text { Wavenumber / } \\
\mathrm{cm}^{-1}\end{array}$ & $\begin{array}{l}\text { IR-Intensity / } \\
\mathrm{KM} / \mathrm{mol}\end{array}$ \\
\hline 127 & 1200.95 & 81.80 \\
\hline 128 & 1217.07 & 113.25 \\
\hline 129 & 1220.30 & 107.25 \\
\hline 130 & 1227.82 & 27.01 \\
\hline 131 & 1231.95 & 566.37 \\
\hline 132 & 1233.70 & 396.38 \\
\hline 133 & 1239.50 & 61.28 \\
\hline 134 & 1249.51 & 58.08 \\
\hline 135 & 1251.79 & 159.46 \\
\hline 136 & 1267.24 & 40.66 \\
\hline 137 & 1270.35 & 8.74 \\
\hline 138 & 1288.03 & 38.49 \\
\hline 139 & 1290.72 & 51.08 \\
\hline 140 & 1303.26 & 29.90 \\
\hline 141 & 1312.36 & 124.46 \\
\hline 142 & 1326.96 & 10.95 \\
\hline 143 & 1344.60 & 31.48 \\
\hline 144 & 1350.20 & 4.79 \\
\hline 145 & 1351.38 & 29.76 \\
\hline 146 & 1393.30 & 10.18 \\
\hline 147 & 1404.96 & 15.04 \\
\hline 148 & 1408.63 & 18.48 \\
\hline 149 & 1414.08 & 10.12 \\
\hline 150 & 1439.37 & 4.78 \\
\hline 151 & 1448.55 & 1.54 \\
\hline 152 & 1473.29 & 11.95 \\
\hline 153 & 1474.40 & 12.50 \\
\hline 154 & 1494.07 & 11.13 \\
\hline 155 & 1502.33 & 33.99 \\
\hline 156 & 1595.45 & 73.54 \\
\hline 157 & 1605.57 & 8.11 \\
\hline 158 & 3078.37 & 0.87 \\
\hline 159 & 3080.39 & 1.02 \\
\hline 160 & 3090.94 & 2.27 \\
\hline 161 & 3091.54 & 2.36 \\
\hline 162 & 3123.50 & 0.08 \\
\hline 163 & 3126.56 & 0.18 \\
\hline 164 & 3139.77 & 0.16 \\
\hline 165 & 3144.78 & 0.21 \\
\hline 166 & 3278.92 & 14.35 \\
\hline 167 & 3284.12 & 33.55 \\
\hline 168 & 3296.00 & 8.85 \\
\hline
\end{tabular}


Figure S6 shows the computed structure of the amphiphilic imidazolium cation with marked direction of the transition dipole vector of the IR vibrations at 1147,1312 and $1351 \mathrm{~cm}^{-1}$ (normal modes 113,141 and 145 , respectively).
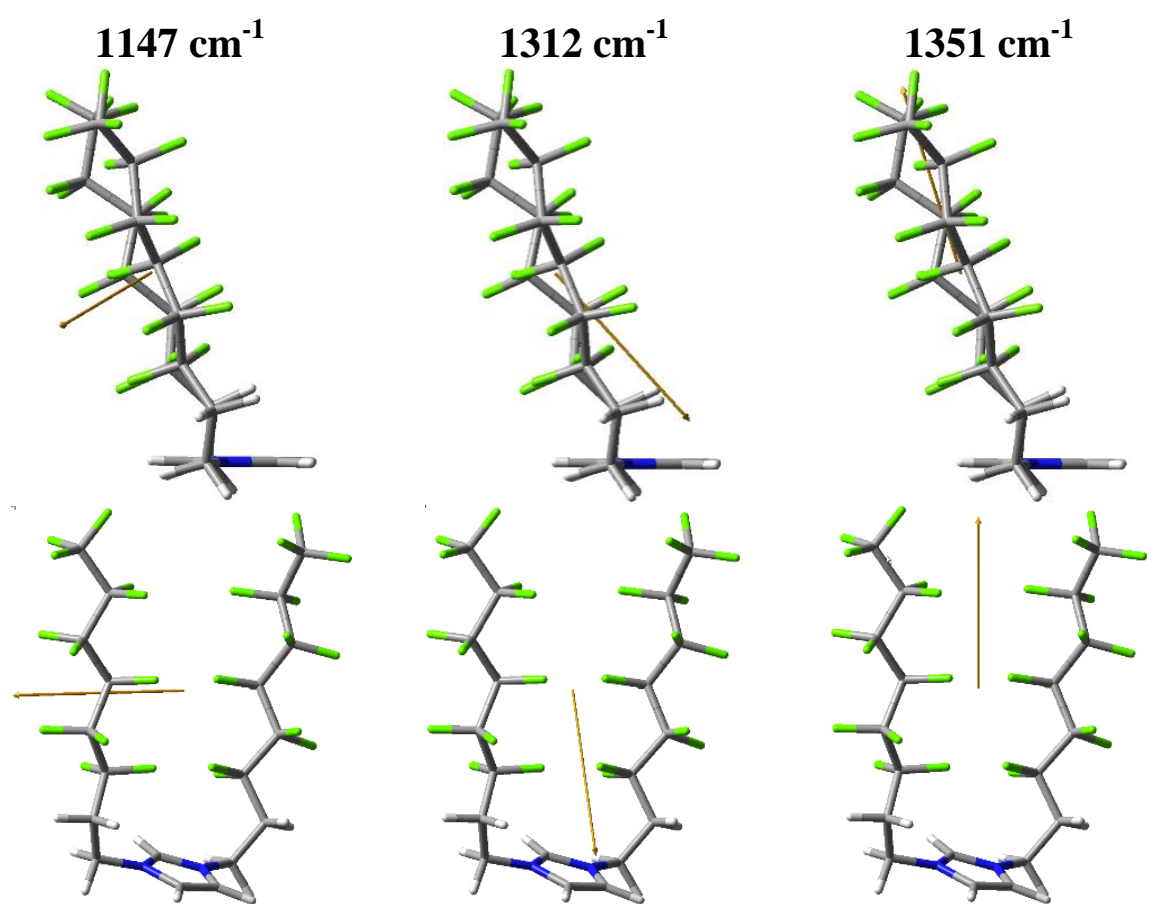

Figure S6. Structure of the amphiphilic imidazolium cation with marked direction of the transition dipole moment vector (orange) of the IR vibration at 1147,1312 and $1351 \mathrm{~cm}^{-1}$ from two perspectives (top and bottom). Color code: $\mathrm{H}$ - white, $\mathrm{C}$ - grey, $\mathrm{N}-$ blue, $\mathrm{F}$ - green.

\section{SI.5 Deconvolution of the PM IRRA Spectra of FILs in LB Monolayers}

The analysis of the orientation of the amphiphilic cation in the monolayer on the gold surface requires the deconvolution of the IR absorption modes contributing to the PM IRRA spectra of the monolayer. The second derivative and Fourier self-deconvolution are used to find the number and position of the maximum of absorption of IR absorption modes contributing to the 1800 $900 \mathrm{~cm}^{-1}$ spectral region. Bands are fitted with Gaussian-Lorentzian sum functions using OPUS v5.5 software (Bruker, Ettlingen, Germany). Several IR absorption modes contribute to this busy spectral region. To gain confidence in the deconvolution procedure, the results of deconvolution are compared to calculated vibration modes calculated for the partially fluorinated $[\mathrm{Im}]^{+}$cation and literature on the IR absorption modes of partially fluorinated fluorocarbon chains. ${ }^{8-10}$ Figure S7 shows the deconvolution of the PM IRRA spectra of randomly distributed [ $\mathrm{Im}]^{+}$cations in the monolayer (a), and of LB-FIL monolayers transferred from both $1 \mathrm{M} \mathrm{NaCl}$ and pure aqueous subphases (b-h). 

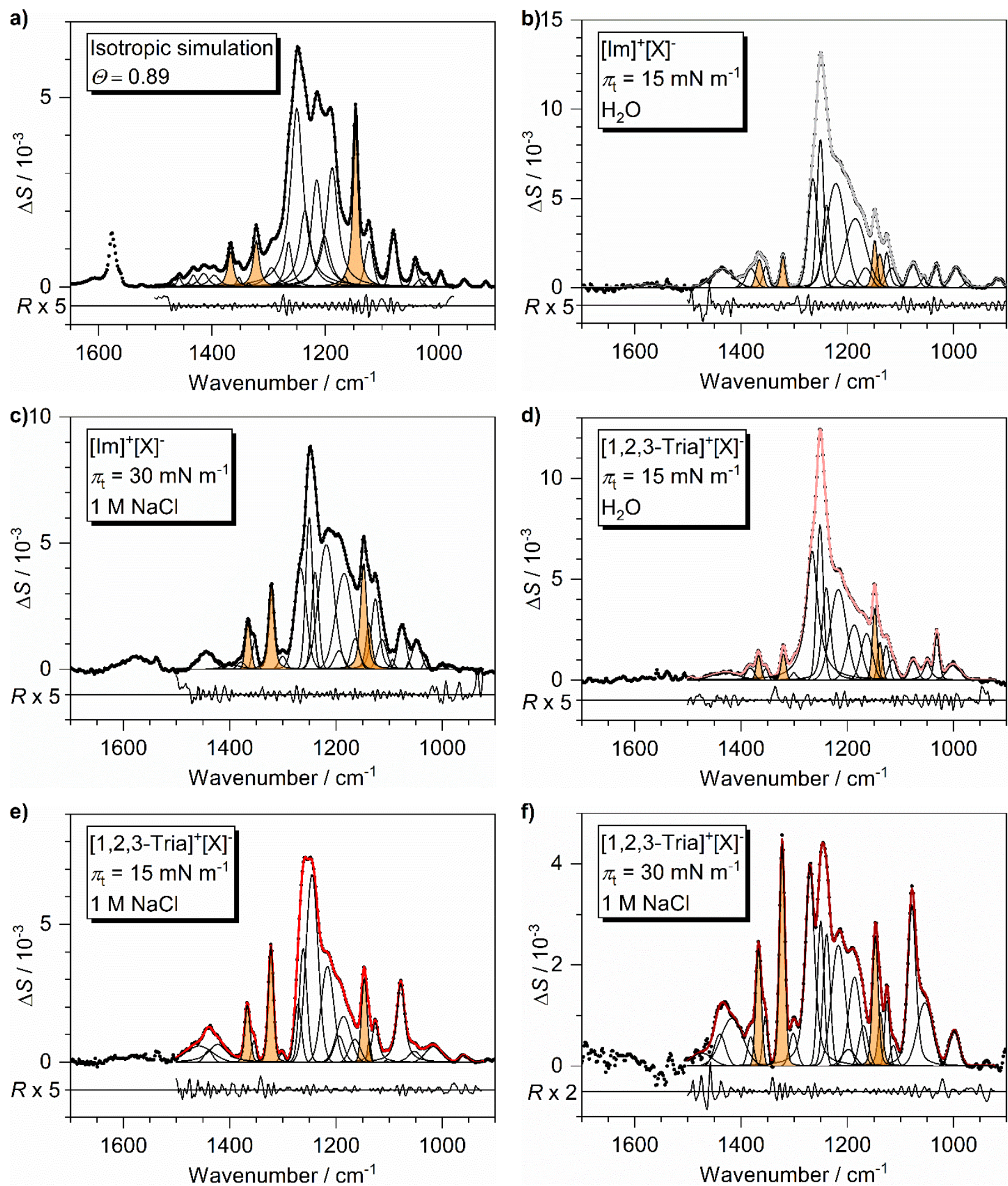

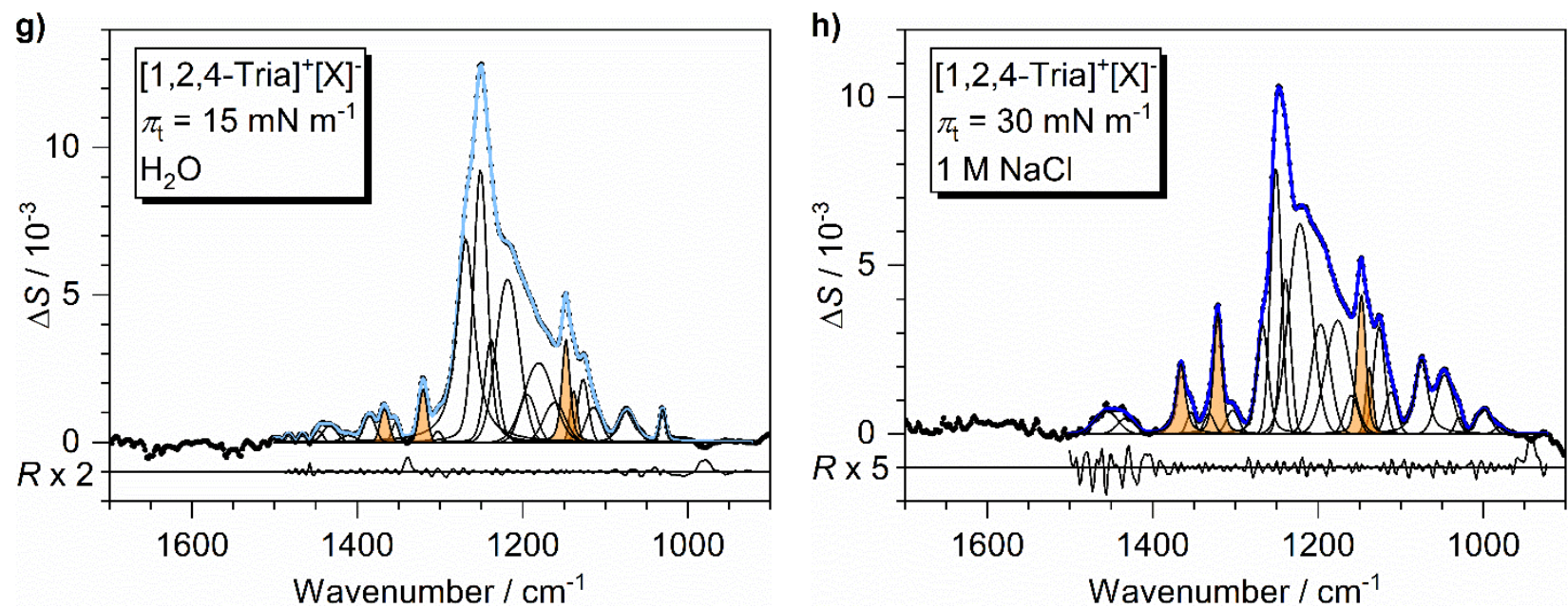

Figure S7. Deconvoluted PM IRRA spectra of FILs: a) simulated spectrum, b) FIL-LB-films with compound and transfer conditions given in inset. Dots - measured, thick line - envelope, thin lines - single band fits. Residuals $R$ shown with magnification below. Bands used for tilt angle determination were colored orange.

\section{SI.6 Contact Angle Measurement}

The contact angles of the FILs in LB monolayers on the gold surface are shown in Table S4. Figure $\mathrm{S} 8$ shows images of $[\mathrm{Im}]^{+}[\mathrm{X}]^{-}$transferred from water and $1 \mathrm{M} \mathrm{NaCl}$.

Table S4. Water contact angles of FILs transferred from water $\left(\pi_{\mathrm{t}}=15 \mathrm{mN} \mathrm{m}^{-1}\right)$ and $1 \mathrm{M} \mathrm{NaCl}_{\mathrm{aq}}$ $\left(\pi_{\mathrm{t}}=30 \mathrm{mN} \mathrm{m}^{-1}\right)$ subphase.

\begin{tabular}{|c|c|c|c|}
\hline FIL & $\pi_{\mathrm{t}} / \mathrm{mN} \mathrm{m}^{-1}$ & Subphase & Water contact angle $/^{\circ}$ \\
\hline$[\mathrm{Im}]^{+}[\mathrm{X}]^{-}$ & 15 & water & $95 \pm 2$ \\
\hline$[1,2,4-\text { Tria }]^{+}[\mathrm{X}]^{-}$ & 15 & water & $93 \pm 1$ \\
\hline$[1,2,3-\text { Tria }]^{+}[\mathrm{X}]^{-}$ & 15 & water & $94 \pm 1$ \\
\hline$[\operatorname{Im}]^{+}[\mathrm{X}]^{-}$ & 30 & $1 \mathrm{M} \mathrm{NaCl}_{\mathrm{aq}}$ & $111 \pm 1$ \\
\hline$[1,2,4-\text { Tria }]^{+}[\mathrm{X}]^{-}$ & 30 & $1 \mathrm{M} \mathrm{NaCl}_{\mathrm{aq}}$ & $109 \pm 1$ \\
\hline$[1,2,3-\text { Tria }]^{+}[\mathrm{X}]^{-}$ & 30 & $1 \mathrm{M} \mathrm{NaCl}_{\mathrm{aq}}$ & $106 \pm 1$ \\
\hline
\end{tabular}

a)

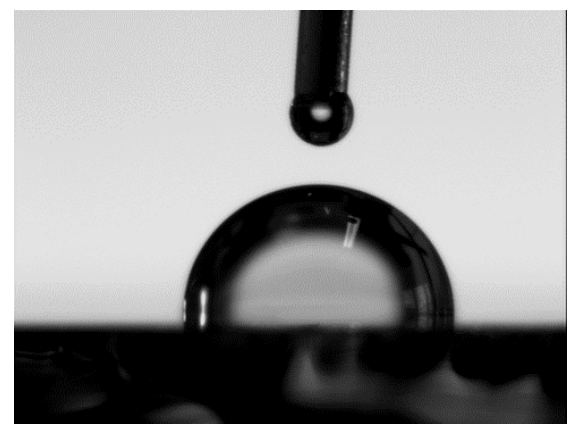

b)

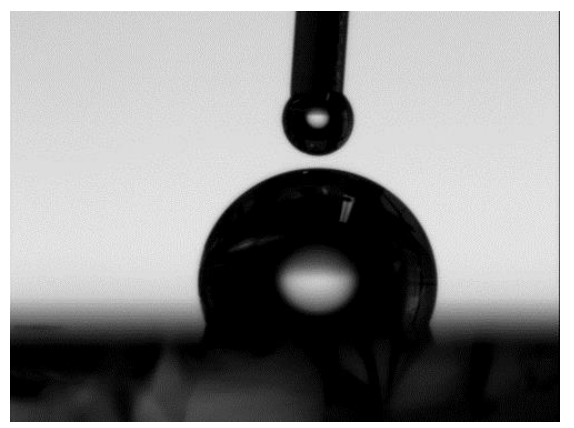

Figure S8. Water contact angles of $[\mathrm{Im}]^{+}[\mathrm{X}]^{-}$transferred from a) water $\left(\pi_{\mathrm{t}}=15 \mathrm{mN} \mathrm{m}^{-1}\right)$ and b) $1 \mathrm{M} \mathrm{NaCl}_{\mathrm{aq}}\left(\pi_{\mathrm{t}}=30 \mathrm{mN} \mathrm{m}{ }^{-1}\right)$ subphase. 


\section{References:}

1. Moulder, J. F.; Stickle, W. F.; Sobol, P. E.; Bomben, K. D., Handbook of X-ray photoelectron spectroscopy. 1 ed.; Perkin-Elmer-Corporation: Minessota, 1992.

2. Martin-Vosshage, D.; Chowdari, B. V. R., X-Ray photoelectron spectroscopy studies on poly-(ethylene oxide) with sodium triflate. J. Electrochem. Soc. 1993, 140 (12), 35313536, DOI 10.1149/1.2221122

3. Alpers, T.; Schmidtmann, M.; Muesmann, T. W. T.; Temme, O.; Christoffers, J., Perfluorinated pyridinium and imidazolium ionic liquids. Eur. J. Org. Chem. 2017, 2017 (29) 4283-4290, DOI 10.1002/ejoc.201700717.

4. Zamlynny, V.; Lipkowski, J., Quantitative SNIFTIRS and PM IRRAS of organic molecules at electrode surfaces. In Adv. Electrochem. Sci. Eng., Alkire, R. C.; Kolb, D. M.; Lipkowski, J.; Ross, P. N., Eds. Wiley-VCH: Weinheim, 2006; Vol. 9, pp 315-376.

5. Palik, E., Handbook of optical constants of solids II. Academic Press: San Diego, 1998.

6. Cordes, D. B.; Smiglak, M.; Hines, C. C.; Bridges, N. J.; Dilip, M.; Srinivasan, G.; Mertlen, A.; Rogers, R. D., Ionic liquid-based routs to conversion or reuse of recycled ammonium prechlorate. Chem. Eur. J. 2009, 15 (48), 134441-13448, DOI 10.1002/chem.20091217.

7. Filipe, E. J. M.; Morgado, P.; Teixeira, M.; Shimizu, K.; Bonatout, N.; Goldmann, M.; Canongia Lopes, J. N., Crystalline-like structures and multilayering in Langmuir films of ionic liquids at the air-water interface. Chem. Commun. 2016, 52 (32), 5585-5588, DOI 10.1039/c6cc01368f.

8. Frey, S.; Heister, K.; Zharnikov, M.; Grunze, M.; Tamada, K.; Colorado, R. J.; Graupe, M.; Shamakova, O. E.; Lee, T. R., Structure of self-assembled monolayers of semifluorinated alkanethiols on gold and silver substrates. Isr. J. Chem. 2000, 40 (2), 81 97, DOI 10.1560/0K18-2RLA-GAQD-NHRU.

9. Hsu, S. L.; Reynolds, N.; Bohan, S. P.; Strauss, H. L.; Snyder, R. G., Structure, crystallization, and infrared spectra of amorphous perfluoro-n-alkane films prepared by vapor condensation. Macromolecules 1990, 23 (21), 4565-4575, DOI 10.1021/ma00223a012.

10. Lu, H.; Zeysing, D.; Kind, M.; Terfort, A.; Zharnikov, M., Structure of self-assembled monolayers of partially fluorinated alkanethiols with a fluorocarbon part of variable length on gold substrate. J. Phys. Chem. C 2013, 117 (37), 18967-18979, DOI 10.1021/jp405475h. 